Speech Acts: The Functionality of Compliments in Contexts

Dr. Ghada Abdullah Al-Ghathami 


\section{Abstract \\ Speech Acts: The Functionality of Compliments in Contexts}

This paper analyzes how compliments are used and what functions they serve in female conversations. It discusses the way compliments are performed and the way they are acted in conversations based on some most frequently used forms and purposes intended by participants. It discusses functions of compliments that express admire, open a conversation and maintain solidarity along with other functions intended by participants. This paper is a case study that investigates compliments occurring in a recorded conversation with emphasis on the functions that were performed in that particular conversation. This paper shows how compliments were performed as acts by Saudi female participants in an informal setting. It also focuses on the structure of these compliments and the intended meanings they conveyed.

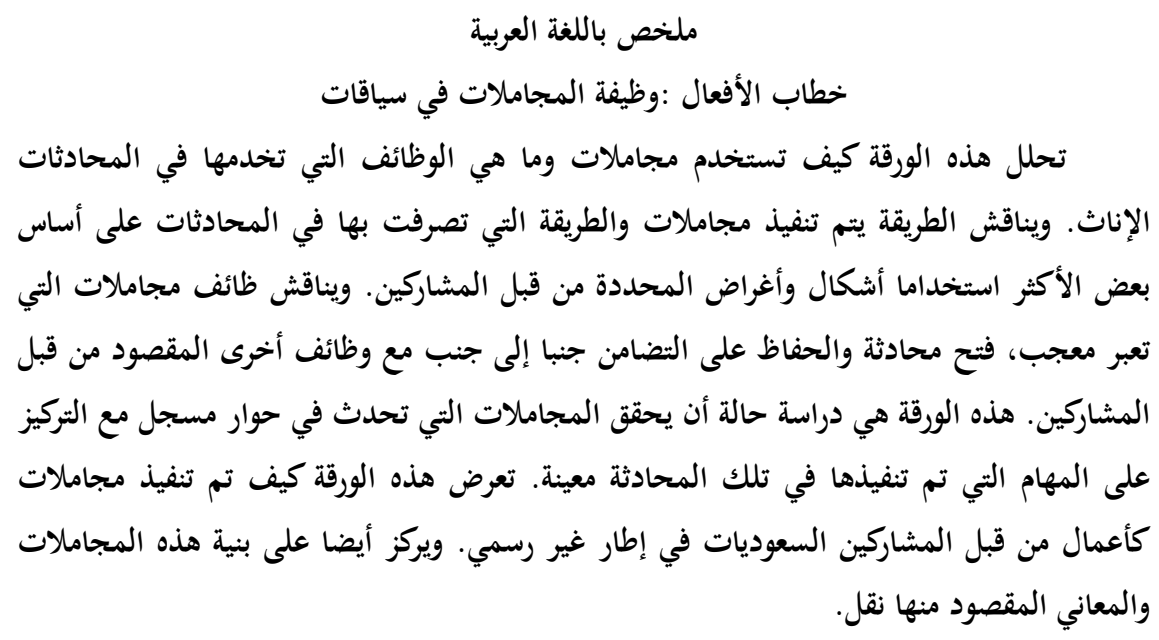




\section{Speech Acts: The Functionality of Compliments in Contexts}

(Case Study)

\section{1- Introduction:}

While conversing, there are utterances that are performed for different communicative purposes. These utterances are known to be acts of speech that are used to perform a certain intended meaning in any given situation. The force of any speech act depends on the context of the utterance. The context where any act of speech is performed determines the purpose and the intention of that speech act. Speech acts are of different types classified based on the purpose they communicate such as requesting, warning, complimenting, offering and others. A compliment is a speech act that is performed by speakers in different circumstances. This speech act has its own functions and its own forms. Some of these forms and functions are discussed in this paper, providing data that investigates this phenomenon.

This paper aims at examining the use of compliments that may occur in natural speech between female participants. The forms and functions of different instances of compliments are discussed. This paper investigates the occurrences of compliments used by female speakers in an informal setting. It also aims at investigating various explanations that may shed light on certain aspects of the situation where certain compliments are encountered. It goes in line with previous studies and also finds otherwise. This paper is divided into several sections where the second section investigates the theoretical background of speech acts. Section three investigates the data of the study. Section four analyzes the data investigating significant compliments that occurred. Section five investigates compliments that developed into events. Section six represents an overall discussion of compliments and section final section concludes the paper and states the findings of the researcher.

\section{2- The Speech Act Theory:}

Speech acts are defined by a number of scholars as these verbal actions that communicate certain functions in certain speech events. These acts are performative and serve as acts of communication. Speech acts are defined by Austin (1962) as verbal actions that communicate certain functions in certain speech 
events, or the act of saying something or performing a locutionary act (p.94). Another definition of speech acts is proposed by Hymes (1989) stating that, "The speech act is the minimal term of the set as the remarks on speech events have indicated. It represents a level distinct from the sentence, and not identifiable with any single portion of other levels of grammar." (p.52). An utterance counts as an act of a certain type if it meets certain socially or institutionally recognized conditions for being an act of that type. Hymes (1986) has also discussed the relationship between speech acts and grammar saying that, "The level of speech acts mediates immediately between the usual levels of grammar and the rest of a speech event or situation in that it implicates both linguistic forms and social norms." (p.57). This statement suggests that speech acts are viewed as linguistic forms that have functions in events and situations.

Speech act theory was originated by the philosopher John Austin and expanded by Searle, (Brown and Yule, 1983; Cutting, 2008; Gee,1999; Johnstone, 2002) a theory that assumes that language is used to perform actions. The theory of speech acts explains and systematically classifies types of speech acts and the ways in which they can succeed or fail. Clark, (2007), talked about the theory of speech acts saying that, "Speech act theory was originated by the philosopher John Austin (1962), expanded by Searle (1969) and developed further by Grice (1975)" (p.57). This theory is based on the assumption that language is used to perform actions, and on how meanings and actions are related to language. According to Mey (2002), speech acts are not only determined by what I say or intend to convey, but they belong to a larger pattern communicated by social individuals that is part of a culture. The way speech acts function in the society is one of the aspects of speech acts that interested scientist by scrutinizing what these speech acts intend to convey. These acts depend on the context of situation that adds contextual meaning to these utterances. The theory of speech acts is concerned with categorizing speech acts into classes where the functions of these utterances are based on their place in the structure of the conversation or interaction (Levinson, 1983).

There are different classifications of speech acts that linguists have adopted. Some linguists classify speech acts 
according to verb types adopting a syntactic approach such as Austin (1962), whereas others base their classifications on meaning, developing big categories and lumps such Searle, along with others that are considered to be splitters where speech acts are classified into hundreds of classes (Mey, 2002). Although speech acts are minimal sets that do not have truth value, they could fail if their conditions are not met or violated (Fasold, 1991).

The success of a speech act is determined by the turn-taking structure by having successive utterances where each utterance is functionally dependent on the previous one. One type of these speech acts is the act of complimenting that has its structures and functions observed in conversations as parts of certain speech events.

\section{Compliments as a Speech Act:}

Compliments are speech acts that are classified under expressive speech acts. They have their particular structures and their specific functions in conversations. According to Hatch (2000), compliments could be used to start a conversation. It could function as a way of encouraging good behavior, or as a sign of thanking. It could also be used to make criticism sound less powerful. Other functions of compliments could include express of admire and maintenance of solidarity.

Compliments can be performed using other structures without having to utter a speech act that can be identified as a speech act of compliment (Mey, 2002). Yet other researchers suggest that compliments have a structure where they could be formed from noun phrases followed by certain verbs (be, look) and an adjective as in (your hair looks nice) which is one of the common structures found for compliments (Hatch, 2000). They usually come at a certain point in the conversation where they come at the beginning of the conversation or as the opening of a new topic. Compliments can be direct or indirect based on the way they are used in speech (Fasold, 1991). They have a structure and a pattern in the conversation since they are usually followed by acceptance or thanks as a response to them. According to Hatch (2000), compliments have a certain structure that can be illustrated as having an opening, which is the compliment act itself, followed by acknowledgement (agree/ deny/ redirect focus), ending with a 
bridge to a new topic. Compliments may be performed by speakers in various forms, serving different functions in interaction.

\section{3- The Data of the Study:}

The data of this study was collected through recording the conversations of female participants in an informal setting. This recording took place in the living room between three sisters and one of their relatives where the recorder was hidden to avoid its influence on the speakers. All participants were Saudi employed female participants in their mid twenties who talked about different uncontrolled choice of topics. The researcher was one of these participants following the approach of the observer- participant method. During the conversation, a number of instances of compliments were performed. Parts of the conversation were transcribed using a broad transcribing system. The conversation that was analyzed as the data of the study was a two-hour conversation. This study is a qualitative study that focuses on forms and functions of compliments following the conversational analysis approach and the interactional sociolinguistics approach as two tools of analysis.

\section{4- The Acts of Compliment in Conversation:}

In a recorded conversation between a group of female participants in an informal family gathering, some compliments were used in different ways. These compliments were communicated in different instances in the conversation and were performed to indicate a number of purposes. Some of the extracts that represent the examples of these compliments are transcribed and included in this section. These extracts are analyzed in terms of their forms and their functions in their social situation to reach a better understanding of the way they were used in the conversation and the functions they served. In a two-hour conversation, a total number of eleven compliments were used in different contexts. These compliments are classified and presented in this section according to their functions in the conversation:

4-1- Compliments Performed to Express Admire:

Some of the compliments that were performed in this conversation were used to express admire. Expressing admire is 
one of the purposes that could be intended by participants through the acts of compliments. The main and most direct implication that could be communicated through compliments is their role in expressing a state of like and admiration, which is the main function of compliments in conversations.

One instance of compliment was performed at the beginning of the conversation where one of the participants (Deema) was complimenting another participant (Tahania) on her ability to travel from one city to the other wearing high-heel shoes. It was performed because (Deema) wanted to express her admire towards (Tahani) because of this action. The compliment was performed at the beginning of this family gathering when (Deema) saw the shoes (Tahani) was wearing when she arrived from the airport to their home. The compliment was performed as in the following extract:

Extract 4-1-1

1- Deema: ! " تهاني, بصر احة أنت مكافحة. جاية من مطار المدينة لهنا بهالجزمة (Tahani, honestly you are a warrior. You came all the way from Almadina airport til here with this shoe!!)

2- Tahani: وش ذا المطار يا كافي

(What an airport is that)

3- Deema: معليش مطاركم فيه درج

(Still, your airport has stairs)

4- Tahani: من هنا لهنا، !وش ذا

(From here to here! It's nothing!)

This act of compliment was performed at the beginning of a family gathering when Deema was surprised from the shoes Tahani was wearing on her trip to Riyadh coming from Almadina. Deema was trying to initiate a conversation and open a topic to communicate with Tahani by performing this compliment expressing her feelings of admire. The act of compliment in this example was formed by the use of an attributive act describing the participant of being a warrior for her ability to walk in those shoes that was performed in line 1. Tahani accepted the compliment but still under-graded her self by contributing to the conversation saying that the airport was too small and it was not an effort that can be recognized. Deema was involved again in the conversation expanding the act of compliment by stating her reason for believing that she deserves this compliment in line 3 saying that the airport has stairs. Her reasoning infers an indirect act of compliment that implies that 
even though the airport was small, it still has stairs, that increased the effort of walking in these uncomfortable shoes.

In line 4, Tahani accepted the compliment again but was being modest about it, saying that Almadina's airport was small and the trip was short and easy. She was trying to say that she did not get tired of wearing these shoes because the airport was small and not because she had a great ability in tolerating high-heel shoes. Even though this act of compliment was performed at the beginning of the conversation to initiate a topic, the real purpose of this act is not to begin a conversation but to express admire. It is Deema's surprise that indicates her admire to Tahani's ability to walk long distances wearing uncomfortable shoes like the one she was wearing in the airport.

Another similar instance where compliments were used to express admire occurred when Rihab expressed her admire of the shirt her cousin was wearing. It took place at a time when there was no serious conversation taking place. There were side- talks when Rihab took the opportunity to express her admire. The instance occurred as the following:

Extract 4-1-2

1- Rihab: تهاني بلوزتلك (^^. •) عاجبتني

(Tahani your shirt $(0,8)$, I liked it)

2- Tahani: لا! عادي تر اها من هنا

(Really! It's nothing, it's from here)

3- Rihab: من وين!

(from where?)

Rihab has initiated her turn by telling her cousin Tahani that she liked her shirt in line 1. She performed this act of compliment by stating her opinion and saying that the shirt is one that she liked. This act was performed mentioning (The shirt) at the beginning of the utterance where (the shirt) was topicalized for emphasis. The word (shirt) was followed by a short pause of less than a second (0.8) to get Tahani's attention indicating that there is something serious to be said about it. This element of excitement was ended when Rihab said she liked the shirt. Rihab has used a verb (liked) in the past form with a present progressive sense in the Arabic language to indicate that she had this interest in the shirt for a while. Tahani has accepted this compliment in line 2 saying that the shirt was not something great as Rihab has said. She also offered 
extra information related to the place where she got it from, saying that she got the shirt from a nearby store, inferring that it was available.

Tahani was being modest again in her acceptance to this compliment by both degrading her shirt and offering related information to express solidarity. Rihab has reacted to that response, asking her about the place where she got it from in line 3 . She asked seeking information since Tahani has offered to share. The act of complimenting, in this example, aimed at expressing admire. The form that was used represents a direct act of compliment, emphasizing the item to be admired in this act.

\section{4-2- Compliments Performed to Open a Conversation:}

Compliments may be performed in conversations to signal an entry to a new topic in the course of the conversation. It may occur at a time where there is no serious conversation taking place, and participants do not have much to contribute. These acts can be both direct and indirect. Compliments usually occur between the opening stage of a topic in any conversation (Hatch, 2000). This indicates the usage of compliments as signals to open a conversation.

In this conversation, one compliment was performed at a point where there was a moment of silence during the conversation after the end of a preceding topic. It was performed while participants were serving tea to each other and there were no turns that were taken. One of the participants (Rihab) had performed an act of compliment about a hand watch that another participant was wearing. The communicative event of complimenting one participant (Bashair) on her hand watch encountered three acts of compliments performed by more than one speaker. These compliments were sequenced as in the following extract:

Extract 4-2-1

1- Rihab: حلوة ساعتلك يا بشاير وشي ذي ؟

(Your watch is beautiful Bashair what is it?)

2- Bashair: سو اتش//)

(Swatch//)

3- Tahani: / سو اتش!)

(Swatch!!)

4- Rihab: صدق، مم + مرة حلوة صح؟ 
(Really, mm+ it's very beautiful right?

5- Tahani: ترى عندي زيها بالضبط لكن العين سماوية buts

(I have exactly the same but its dial is blue)

In this extract, three compliments were performed. The first compliment was produced by Rihab, describing the beautiful watch Bashair was wearing. The form of this act was a direct form that was structured by the use of the adjective (beautiful) to give a statement of liking the watch, followed by a question about the brand of the watch. This form Rihab used indicated both stating admire and seeking information. It also indicated a need of acceptance by Bashair since Rihab used the question to select her as the next speaker, waiting for her approval. This act was followed by an acceptance on behalf of Bashair by taking the turn allocated to her, and providing the brand of the watch (Swatch) in line 2 as a required answer to the direct question that was asked. Tahani at that point initiated her turn and repeated the name of the brand (Swatch), indicating her surprise in line 3. This participation could also be considered an indirect compliment inferring that the watch did not look as one that was produced by this company.

The second act of complimenting was performed by the first speaker (Rihab), indicating that the watch was beautiful regardless of its brand. This took place in line 4. It her turn, (Rihab) asked saying, (really?!) expressing her surprise that the watch was produced by that brand name. This question was not asked as an answer-seeking device, but it was asked to express surprise. This question was followed by a statement, which indicated that the watch was still very beautiful. This act also took the same form, which is the use of an adjective along with an adverb of frequency followed by a tag, asking for support by other speakers as in, (It's very beautiful, right?). This act was used at this point to show greater admiration of the watch. The third act of compliment took place at a point where support was needed when the speaker (Tahani) supported Rihab's compliment that was followed by a tag giving an indirect compliment in line 5. This indirect compliment was implied from the statement (Tahani) had communicated when she said that she had a similar watch but in a different color. The implication was that Bashair's watch was beautiful that she actually had the same watch but in a different color, which explains her surprise. This last act of compliment was performed to support the 
previous acts performed by the other speaker showing solidarity. These acts of compliments took place at different points in the conversation where one was performed at the beginning of the conversation to signal a new topic, which was the event of compliment in this case. The second act was performed to express admire supporting the topic in order for it to circulate by other participants. The third compliment was performed to express solidarity, where there was a need by other speakers to be supported.

Another instance of compliment has occurred in the conversation for the purpose of opening a new topic. It took place at a moment of silence where there was no topic under discussion and participants were waiting for a topic to be introduced and suggested. Participants were not talking and the turn taking system was not circulated. The compliment was acted when Rihab commented on Tahani's new hair color that she has recently done, saying that it looked nice on her. It was performed and developed by participants as in the following extract:

4-2-2

1- Rihab: حلوة صبغتلك

(Your hair color is nice)

2- Tahani: ورلّ

(Really?)

3- Deema: لايقتلها

(It suits her)

4- Rihab: إب

(Ya)

5- Tahani: إي. شكر ا. ترى هذي أنا مسويتها في البيتً

(Ya. Thanks. You know, I did it at home)

In this extract, a compliment was performed by Rihab in line 1, when she directly conversed with Tahani, saying that her new hair color was nice. This compliment was direct and took the form of description using the attributive form as in, (Your hair color is nice). The use of the adjective (nice) indicates that the hair color was not in place of great admiration by Rihab. If the complimenting speaker sincerely admired the hair color, she would have used a stronger adjective and a longer description to express admiration. The situation in that case indicates that this particular act was performed to start a new topic and rescue the conversation. 
Tahani reacted upon this compliment saying, (really?) questioning the statement that was proposed by Rihab in line 2. Tahani's question implies that she did not really accept the compliment since she was not sure herself that this hair color looked nice on her. She dealt with it as an attempt to fill in a gap in the conversation, and wanted confirmation from Rihab allocating the turn back to her to confirm what she said about the hair color.

At that point, Deema took the turn and involved herself in the conversation confirming that the hair color suited Tahani and was nice on her in line 3. Deema's contribution indicated that her compliment was performed to express solidarity and support. It took the form of a direct compliment. Rihab also supported Deema in return agreeing on what she said and confirming her approval in line 4. This agreement was needed from both participants (Deema and Tahani). Deema needed it for support and Tahani needed it to confirm the first initiated compliment. Tahani responded to these three compliments agreeing with both participants that this color looked nice on her in line 5. She also thanked them for their compliments. Since she accepted the compliment, she also accepted the topic that was introduced and carried out her turn saying that she did the coloring herself at home. Talking about this experience led to accepting this topic as a new topic, which was in place of interest by participants. It can be noted that there was a slow turntaking circulation in this conversation where not much involvement is noticed. This could result due to less interest in this topic by other participants, or due to less interest in the compliment itself. Most of these turns were short and quick. This conversation was continued successfully when Tahani initiated the actual topic, which was about hair coloring after she accepted the compliment. In this extract, three compliments can be noted where the first one was performed to open a new topic after a period of silence. The other two compliments were performed to show solidarity and support to other participants in the conversation in a network of acts that had different purposes.

\section{4-3- Compliments Performed to Maintain Solidarity:}

Compliments can also be performed in conversations to maintain solidarity among participants. This function could be present in female conversations where they tend to express 
solidarity more frequently than men. Female language style is based on conversational facilitation strategies leading to create solidarity where female participants communicate by supporting each other. Litosseliti (2006) has mentioned that, "Women treat conversations and gossip as co-operative work that requires a lot of positive feedback and prompting, and avoids indirect disagreement." (p.39). Women tend to express their emotions performing acts that refer to the way they feel, and they are more likely to apologize, compliment and make self-directed statements producing solidarity among members of the same sex, (Weatherall, Watson and Gallois, 2007).

An example of a compliment that was performed to express solidarity has occurred in the middle of this conversation when participants were talking about a pair of jeans that they found at the mall. They were discussing whither this pair of jeans they found would be suitable for one of them. Since this participant believed that she was short to wear such an outfit, she needed support by other speakers to convince her that it suited her. The other participants cooperated with each other in this act showing their solidarity. The compliment occurred in the conversation as in the following extract:

Extract 4-3-1

1- Tahani: يختي ما يطلع علي حلو

(It doesn't look nice on me)

2- Deema: إلا بالعكس إلا

(Yes it does yes)

3- Rihab: / أماني قصبرة و لابستو وطلع عليها حلو /

(Amani is short and she wore it and it looked nice on her //)

4- Deema: إي بالعكس هو عالبتيتين احلا

(Yes on the contrary, it is nicer on petites.)

In this extract, Tahani was not interested in getting a particular pair of jeans since she believed that it would not suit her since she was short. In line 1, she stated that it would not look nice on her even though she liked it. Her utterance was performed seeking support where Tahani was being intimate about this issue. Deema in line 2 used an indirect form to compliment Tahani expressing a contrary thought. She inferred that it should fit beautifully as opposed to what Tahani was thinking. She performed this act to show solidarity. Her act was indirect by stating that this pair of jeans 
would look nice on her, complimenting her figure. Another speaker has also complimented Tahani in line 3 by admiring her figure through giving an example of a girl who was as short as her, and yet it looked nice on her. This act of compliment was an indirect compliment where it implicated that she looked nice. The function of this compliment was to soften the criticism and to save Tahani's face that was threatened. She also used this compliment to express solidarity and support to Deema's thought.

Deema has also supported the compliment performed by Rihab by performing another indirect compliment saying that this pair of jeans would look nice on petites in line 4 . This act was performed to implicate that Tahani is a petite girl and has a great figure. This act is an indirect act providing examples and justifications that indicate a state of compliment. It was performed by Deema to express her solidarity to both participants Tahani and Rihab. She was expressing her feelings about Tahani's nice figure. On the other hand, she was trying to support Rihab's compliment showing solidarity since they both tried to maintain a cooperative conversational style where both were supporting the turns of each other. These three acts of compliments occurred in this exchange were performed to show support and maintain solidarity between members involved in this conversation.

\section{5- Compliments Developed into Events:}

Compliments could develop in certain situations from being sets of acts into an entire event by itself. The event structure of a compliment can be described according to a certain applied structure which is: compliment + acknowledgement/ acceptance + bridge (Hatch, 2000). Compliment acts can also be viewed under the structure of adjacency pairs in which there is a verbal exchange that is familiar and expected (May, 2002). These utterances are in an exchange governed by their type and their function. In such a case, this regular pair structure is connected with structured speech acts (Mey, 2002). Speech acts are viewed as minimal sets; yet, they can develop into extended speech events where acts may recycle into several minimal sets within the same conversation, (Hymes, 1989). This could happen if the interlocutor is not accepting the compliment act, especially where more compliments are needed. In 
this section, an example that illustrates how compliment acts can develop into compliment events is represented.

An instance where an act of compliment developed into an event took place when (Deema) was trying a new dress she thought did not look good on her. She was planning to go to her friend's wedding and was not sure what to wear. She was confused between two dresses and thought that her dress looked bad on her. She was trying to convince the others that her dress is not appropriate and it would be a good idea if she would wear her sister's dress instead. The other participants in the conversation were trying to convince her to accept her dress. They were trying to raise her selfconfidence by performing a sequence of compliments in different forms as in the following extract:

Extract 5-1

1- Rihab: وريني،

(Show me,)

2- Tahani: $\gamma \nabla$

(No no)

3- Rihab: بالعكس مرة حلو + ازين من حق أبر ار

(On the contrary it's very beautiful + it's better than Abrar's)

4- Deema: شوفو شكلي وشو هذا

(Look at me what is this!)

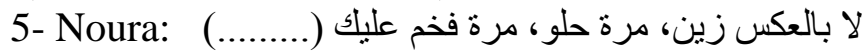

(No on the contrary it looks nice, very beautiful, very elegant on you $(\ldots . .)$.

6- Tahani: مرة حلو + كأنه جاهز + صح

(Very beautiful+ it looks like a couture +right?)

In this extract more than one compliment was offered to Deema at a time when she was wearing a dress that she did not really liked. Rihab in line 1 asked Deema to turn around and show off the dress. The first compliment occurred when Tahani said (No no) in line 2 that took the form of negating a previous assumption provided by Deema herself assuming that the dress was not nice. This act is an indirect act that took the form of expressing negation. It can be implicated from this statement that it was a compliment since it indicated an opposite statement, expressing that the dress was not bad as Deema had suggested. At that point, Rihab had supported Tahani's compliment performing another direct compliment using the form of (adverb+ adjective) describing the dress. She also 
carried on with her act comparing this dress to her sister's dress (that Deema believed to be very nice), saying that it even looked better. The function of both compliments was to show both support and admire. On the other hand, Deema has responded to both compliments by showing a hesitated acceptance saying that they should look closer to the way she dressed, in line 4. This statement indicated that she was not totally accepting these two compliments and had doubts about them.

From Deema's statement, it can be understood that she demanded more compliments to support her confidence in the dress. Noura has took a turn at that point accepting Deema's need for a compliment and offered her one, assuring Deema that it was not like what she was thinking. This act took the form presenting a contrary thought of approval followed by two phrases that consisted of an adverb followed by an adjective that were used twice, "very beautiful, very elegant" using both direct and indirect acts at the same time. Tahani has also performed another compliment supporting Noura's compliment in line 6. Tahani also used the same form which is an adverb followed by an adjective. She also expanded her compliment giving a simile (That it looked like a couture) and closed her act with a tag question seeking the support of other participants.

These compliment acts functioned to show support and admire at the same time presenting a network of functions. Each member of the conversation had a turn in this complimenting event where they performed around twelve acts of compliments in the same context referring to the same person where they all cooperated with each other in an attempt to support Deema. This example shows a contrary function that does not represent general functions and structures that were suggested in the literature. This example illustrates a structure that was observed in a Saudi female conversation in which these compliments recycled several times involving all participants, aiming at supporting one of them by using forms that varied from direct to indirect forms. The act of compliment in this case did not involve a bridge to another topic. On the contrary, it became a topic by itself where it developed from a single act to a cluster of acts that included around twelve acts along with the ones that were mentioned in extract 6-1 in this section. 


\section{6- The Overall Functions of Compliments in the Conversation:}

In this paper, four different functions of compliments were discussed and presented with examples of extracts that were taken from the recorded conversation between Saudi female participants in an informal family gathering. The analysis of these extracts was based on understanding the context where these acts of compliments were performed. The forms of these compliments varied from direct to indirect acts. To understand the functions of compliments performed in this conversation, their numbers along with their functions were summarized. The following table represents each function of compliment acts along with their number of occurrences in the conversation:

Table 1: Functions and numbers of compliments in recorded conversations

\begin{tabular}{|l|l|l|}
\hline Functions of compliments & $\begin{array}{l}\text { Number of } \\
\text { Occurrence }\end{array}$ & Example \\
\hline 1- Expressing admire. & 3 compliments. & $\begin{array}{l}\text { Extract 4-1-1, extract 4- } \\
1-2\end{array}$ \\
\hline 2-Opening a conversation & 3 compliments. & $\begin{array}{l}\text { Extract 4-2-1, extract 4- } \\
2-2\end{array}$ \\
\hline 3- Maintaining solidarity. & 5 compliment. & Extract 4-3-1 \\
\hline $\begin{array}{l}\text { 4- Other functions } \\
\text { (Acts developed into events). }\end{array}$ & $\begin{array}{l}1 \text { compliment event } \\
\text { that included around } \\
16 \text { compliment acts. }\end{array}$ & Extract 5-1 \\
\hline Total number compliments: 12 compliments. \\
\hline
\end{tabular}

The importance of this paper is not only in investigating the functions these compliments serve in the conversation, but also in the way they were performed. To sum up, these Saudi female participants performed four main functions of compliments in this conversation. One of these functions is expressing admire at times where participants felt interested in performing these acts to show a state of like. Another function is opening a conversation where there was less interest in a certain topic by participants, resulting in performing these acts as a bridge that led to another more interesting topic. Compliments were also performed in some parts of the conversation expressing solidarity among participants as suggested by other findings, (Litosseliti, 2006). The fourth function of compliments was the development into a complimenting event 
where a compliment was developed from being a minimal set of acts into an extended event as opposed to other findings.

These functions of compliments seem to interrelate in some instances in the conversation where more that one function was intended in the same exchange. A participant could perform an act of compliment to start a conversation whereas other participants may perform a compliment to show support to other participants in the same event. These compliments may be accepted or denied by the participant receiving the compliment. Some participants may demand further compliments to be performed for them to accept this act. A diagram that may illustrate the direction of these compliments is shown as the following:

Diagram summarizing compliment direction in conversations

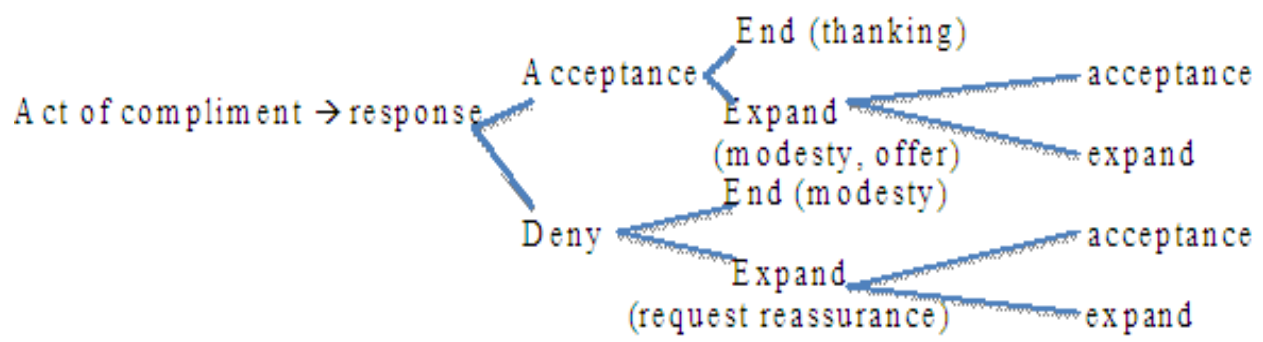

Because participants belonged to a similar age group, similar level of education, status and class, most compliments where performed on basis of solidarity and support. Even though this paper identifies four types of functions, others can be noticed.

\section{8- Conclusion:}

In this paper, the instances of compliment acts that were performed were investigated based on both their forms and functions. These acts of compliments were examined according to their place and role in the conversation, and were classified according to the functions they served in the course of the conversation. A number of studies have investigated these compliment acts focusing on aspects of their use and structure. The findings of this paper go in line with similar findings of scholars and findings of similar research papers, indicating that compliments may be performed by conversationalists, using sets of forms that could take the form of 
direct acts or indirect acts. These compliments also served a number of functions in different situations. The findings of this paper also contradict with other findings since there were instances of compliments in the data, suggesting that these acts may function in a different manner.

These acts of compliments performed occurred in a verity of structures that took forms such as the attributive use, description, negation and example giving. Compliments were also performed in both direct and indirect forms. They also communicated different functions that were classified into four types of functions. One of the functions of compliments in this conversation was the function of expressing admire and like. Other functions that were communicated by these acts were the function of initiating a conversation and the function of expressing solidarity. The fourth function of compliments that was discussed in this paper was related to an instance where a network of functions of compliment acts was performed in a single exchange where this act developed from an act into an extended event including sets of compliments.

Further research needs to be carried out to investigate the role of compliments in conversations searching for other functions that can be intended by speakers. Other extended research is also needed to examine other possible forms and structures that can be performed in both direct and indirect forms. Extended research is also needed to investigate other variants that may affect the use, function and structure of compliments such as formal settings, gender and age. 


\section{References:}

Austin, J. (1962). How to Do Things with Words. Cambridge: Cambridge University

Press

Brown, G., \& Yule, G. (1983). Discourse Analysis. Cambridge:

Cambridge

University Press.

Clark, Urszula. (2007). Studying Language: English in Action. Macmillan, Palgrave.

Cutting, J. (2008). Pragmatics and Discourse. Second edition. London: Routledge.

Fasold, Ralph. (1991). The Sociolinguistics of Language. Blackwell, Basil.

Gee, J. P. (1999). An Introduction to Discourse Analysis Theory and Method.

London: Routledge.

Gumperz, John., Hymes, Dell. (1986). Directions in Sociolinguistics: The

Ethnography of Communication. Blackwell, Basil.

Hatch, Evelyn. (2000). Discourse and Language Education. Cambridge University

Press, Cambridge.

Hymes, Dell. (1989). Foundations in Sociolinguistics: An Ethnographic Approach.

University of Pennsylvania Press, Philadelphia.

Johnstone, B. (2002). Discourse Analysis. London, Blackwell Publishing.

Levinson, S. (1983). Pragmatics. Cambridge University Press, Cambridge.

Litosseliti, L. (2006). Gender and Language: Theory and Practice. Hodder Arnold,

New York.

Mey, J. (2002). Pragmatics: An Introduction. Second edition. Blackwell Publishers,

London.

Weatherall, A., Watson, B., Gallois, C. (2007). Language, Discourse and Social

Psychology. Palgrave Macmillan, New York. 